\title{
Exertional heat stroke in a marathon runner with extensive healed deep burns: a case report
}

\author{
Puneet Seth ${ }^{1,2,3^{*}}$ and Poh Juliana ${ }^{1,2,3}$
}

\begin{abstract}
Exertional heat illness typically occurs over hours in younger athletic patients or military recruits who exercise at elevated temperatures for a sufficient period of time to cause the rate of heat production to exceed the capacity of the body to dissipate heat. Since the physiological response to exercise includes cutaneous vasodilation and sweating, any limitation of such a response can cause rapid hyperthermia and thus heat stroke. One such condition is extensive burns healed by cicatrisation of the skin where the scar and grafted skin surface do not have functional sweat glands and are unable to lose heat in response to high temperatures. The authors report one unique case of a female marathon runner with exertional heat stroke who had recovered from deep second and third degree burns over approximately $50 \%$ of her body a few years ago.
\end{abstract}

\section{Introduction}

Exertional heat injuries are known to affect marathoners and army recruits under hot and humid environmental conditions $[1,2]$. This occurs when heat production exceeds the body's ability to dissipate heat. Since peripheral vasodilation and sweating can dramatically increase heat loss, the lack of these physiological responses seriously predisposes those with these conditions to exertional heat injuries. The authors report a unique case of a female marathon participant who suffered exertional heat stroke possibly caused by her inability to sweat over a large surface area of her body and thus accumulating heat rapidly.

\section{Case report}

A 36-year-old female who had been running a marathon was brought to the emergency department (ED). She was brought in by the Civil Defence ambulance after she had collapsed at the $10 \mathrm{~km}$ mark. According to bystander accounts, she was unresponsive, trembling and her eyes were rolling up. There was no jerking of the limbs to suggest a generalised seizure according to the paramedics.

The patient's sister, who was running ahead of her, said that the patient had been well before the marathon

\footnotetext{
* Correspondence: pseth15@hotmail.com

'Department of Emergency medicine, Singapore General Hospital, Singapore.
} Full list of author information is available at the end of the article and that both had flown in from Australia for the event. The patient used to run regularly, but shorter distances.

On arrival, the patient was noted to be obviously confused and disorientated, and kept trying to get off the bed. Her rectal temperature was $41.6^{\circ} \mathrm{C}$ initially and dropped to $38.4^{\circ} \mathrm{C}$ at the emergency department. The heart rate was 120 beats/min, blood pressure was 91/48 $\mathrm{mmHg}$, and the oxygen saturation was $98 \%$ on room air. Normal saline was administered through an iv cannula in the left antecubital fossa. The cardiovascular and abdominal examination was unremarkable. She was able to move all four limbs, and her pupils were equal and reactive to light.

She was noted to have extensive scarring all over her trunk and upper limbs except the hands and the upper part of her face. Previous case records showed that she had sustained deep second and third degree burns over $49 \%$ of her body 5 years earlier. This condition was complicated by the development of a deep vein thrombosis of the right lower limb. The cicatrised skin was noted to be rubbery, firm, dry and shiny (Figure 1).

Rapid evaporative cooling using wet gauze to moisten the skin and pedestal fans at $22^{\circ} \mathrm{C}$ was employed. One litre of normal saline was infused via two intravenous lines. The patient became progressively calmer, but stayed amnesic throughout her stay at the ED.

Her renal function, liver function and coagulation profile remained within normal limits at all times. Electrolytes showed the presence of some compensated

\section{SpringerOpen ${ }^{\circ}$}

(C) 2011 Seth and Juliana; licensee Springer. This is an Open Access article distributed under the terms of the Creative Commons Attribution License (http://creativecommons.org/licenses/by/2.0), which permits unrestricted use, distribution, and reproduction in any medium, provided the original work is properly cited. 


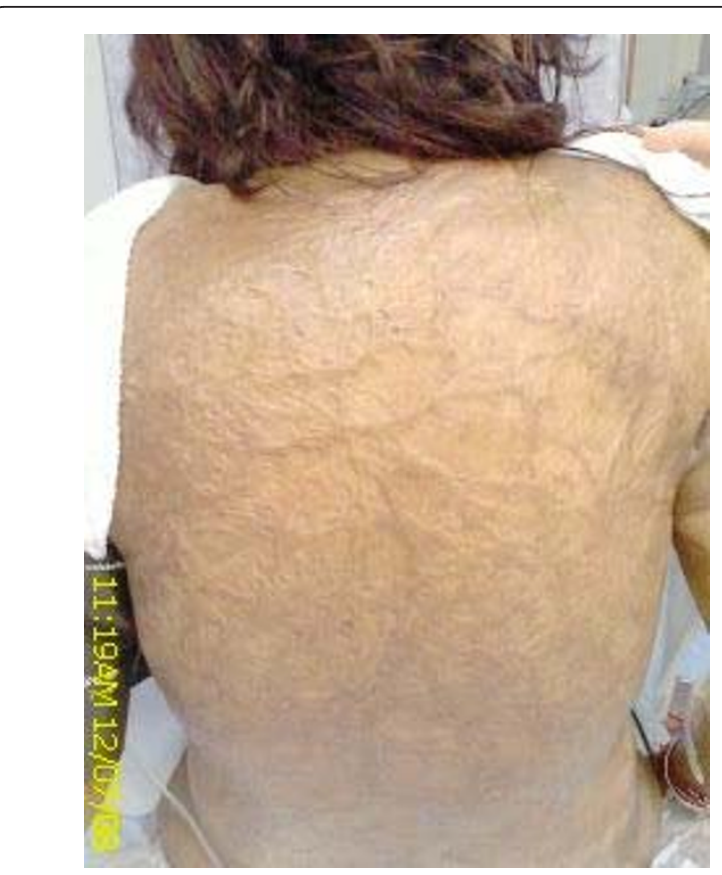

Figure 1 Skin on the patient's back.

metabolic acidosis ( $\mathrm{pH} 7.40) ; \mathrm{pCO}_{2}$ was $28.2 \mathrm{mmHg}$, $\mathrm{pO}_{2} 98 \mathrm{mmHg}$ and serum bicarbonate $16 \mathrm{mmol} / \mathrm{l}$. Base excess was -7.3 (normal -2 to +2 ). Her creatinine kinase levels peaked at about 2,096 U/l (range: 38 - 164 U/l) before trending downwards. The urine myoglobin level was noted to be a maximum of $100 \mathrm{UG} / \mathrm{l}$ (normal $<21$ UG/l).

The patient was admitted to the medical ward and stayed there for 3 days. She regained her normal mental state by the evening of the same day. She was eventually discharged with advice to refrain from participating in any such endurance events because of her singular physiology.

\section{Discussion}

Heatstroke is traditionally divided into exertional and classic varieties $[3,4]$, which are defined by the underlying aetiology, but are clinically indistinguishable. Exertional heat illness typically occurs over hours in younger athletic patients or military recruits who exercise at elevated temperatures for a sufficient period of time to cause the rate of heat production to exceed the capacity of the body to dissipate heat. Since the physiological response to exercise includes vasodilation and sweating, any limitation of such a response can cause rapid hyperthermia and thus heat stroke.

The body's ability to dissipate heat by perspiration can be overwhelmed in subjects with normal physiology under extreme conditions. The role of adequate and appropriate rehydration before and during exercise has always been emphasised. This is because it is presumed that the increased heat production and the resultant increase in the core body temperature will drive the peripheral vasodilation and that the sweat secretion rate will increase proportionately to enhance heat loss. This has been established in numerous studies [4,5]. However, it is also known that this proportionate increase in the heat-releasing compensatory mechanism is limited to a certain level beyond which it is overwhelmed and the patient develops hyperthermia.

The present case is unique. The patient had sustained deep second and third degree burns over $49 \%$ of her body 5 years earlier, which had healed with the formation of a cicatrix. While some sweat glands may survive superficial second degree burns, most are destroyed or rendered nonfunctional in deep second degree burns ${ }^{7}$. Additionally, the patient went through multiple partial thickness skin grafting procedures, and such grafts are known to have no sweat glands.

Thus, the patient was left with only about half of her body surface area able to dissipate heat by perspiration and vasodilation. This was probably not enough to maintain normothermia during her marathon endeavour.

Some investigators have pointed out that under moderate conditions of heat, the remaining normal skin can compensate by increased sweating [6,7]. The exact percentage of normal skin required is not known, but is inferred to be in the range of $50-70 \%$ based on some studies $[8,9,7]$. Roskind et al. found a dramatic diminution in heat tolerance in patients with healed burns covering more than $40 \%$ of their body surface area [10].

While there is definite scope for further studies in this area, it is perhaps safe to conclude that persons with deep burns to more than $30-40 \%$ of their body surface area should be advised against participation in any endurance sports or working in high ambient temperature conditions to avoid heat injury.

\section{Acknowledgements}

Consent Statement: Written informed consent was obtained from the patient for publication of this case report and accompanying images. A copy of the written consent is available for review by the Editor-in-Chief of this journal.

\section{Author details}

${ }^{1}$ Department of Emergency medicine, Singapore General Hospital, Singapore. ${ }^{2}$ Academy of Medicine, Singapore ${ }^{3}$ Royal College of Surgeons of Edinburgh, Edinburgh, UK.

\section{Authors' contributions}

PS compiled the records and initial draft of the report. JP helped with the discussion and editing the manuscript.

\section{Competing interests}

The authors declare that they have no competing interests. 


\section{References}

1. Seto CK, Way D, O'Connor N: Environmental illness in athletes. Clin Sports Med 2005, 24(3):695-718, x.

2. Coris EE, Ramirez AM, Van Durme DJ: Heat illness in athletes: the dangerous combination of heat, humidity and exercise. Sports Med 2004, 34(1):9-16

3. The Evaluation and Management of Heat Injuries in the Emergency Department. EMP 2006, 8(6)

4. Simon HB: Hyperthermia. N Engl J Med 1993, 329:483,

5. Moshe Rav-Acha, Eran Hadad, Yoram Epstein, Yuval Heled, Moran Daniel S: Fatal exertional heat stroke: a case series. Am J Med Sci 2004, 328:84.

6. Shapiro Y, Epstein Y, Ben-Simchon C, Tsur H: Thermoregulatory responses of patients with extensive healed burns. J Appl Physiol 1982, 53:1019-1022, 8750-7587/82.

7. Wilmore DW, Mason AD Jr, Johnson DW, Pruitt BA Jr: Effect of ambient temperature on heat production and heat loss in burn patients. J Appl Physiol 1975, 38(4):593-7.

8. Xiao-bing Fu, Tong-zhu Sun, Xiao-kun Li, Zhi-yong Sheng: Morphological and distribution characteristics of sweat glands in hypertrophic scar and their possible effects on sweat gland regeneration. Chin Med J 2005, 118(3):186-191.

9. McGibbon B, Beaumont WV, Strand J, Paletta FX: Thermal regulation in patients after the healing of large deep burns. Plast Reconstr Surg 1973, 52(2):164-70.

10. Roskind JL, Petrofsky J, Lind AR, Paletta FX: Quantitation of thermoregulatory impairment in patients with healed burns. Ann Plast Surg 1978, 1(2):172-6.

doi:10.1186/1865-1380-4-12

Cite this article as: Seth and Juliana: Exertional heat stroke in a marathon runner with extensive healed deep burns: a case report. International Journal of Emergency Medicine 2011 4:12.

\section{Submit your manuscript to a SpringerOpen ${ }^{\circ}$ journal and benefit from:}

- Convenient online submission

- Rigorous peer review

- Immediate publication on acceptance

- Open access: articles freely available online

- High visibility within the field

- Retaining the copyright to your article

Submit your next manuscript at $\gg$ springeropen.com 